\title{
Prevalence of Metabolic Syndrome in Obese Saudi
}

\author{
Khalid S Aljabri ${ }^{1 *}$, Samia A Bokhari ${ }^{1}$, Muneera A Alshareef ${ }^{1}$, Patan M Khan ${ }^{1}$ and Bandari K Aljabri ${ }^{2}$ \\ ${ }^{1}$ Department of Endocrinology, King Fahad Armed Forces Hospital, Saudi Arabia \\ ${ }^{2}$ College of medicine, Um Al Qura University, Makkah, Saudi Arabia
}

*Corresponding author: Khalid S J Aljabri, Department of Endocrinology, King Fahad Armed Forces Hospital, Jeddah, Kingdom of Saudi Arabia, Jeddah 21159, PO Box 9862, Saudi Arabia

Submission: 眥 July 19, 2018; Published: 䟧 August 31, 2018

\begin{abstract}
Background and Objective: Metabolic syndrome (MetS) is a cluster of metabolic factors. The prevalence of MetS are increasing worldwide. The aim of this study was to determine the prevalence of MetS in obese Saudi population.

Methods: We analyzed 1526 obese participants who are equal to or older than 18 years old. All cases were from the population of the primary health at King Fahad Armed Forces Hospital. All data were collected by personal interview and on the basis of a review of electronic medical records. Physician and nurse interviewers measured and recorded weight $(\mathrm{kg})$ and height $(\mathrm{cm})$. Metabolic risk factors were defined using the $2006 \mathrm{International}$ Diabetes Federation criteria that define elevated triglyceride (TG) as $\geq 150 \mathrm{mg} / \mathrm{dL}(\geq 1.7 \mathrm{mmol} / \mathrm{L}$ ) and reduced high density lipoprotein (HDL) as $<40 \mathrm{mg} /$ $\mathrm{dL}(<1.03 \mathrm{mmol} / \mathrm{L})$ for male and as $<50 \mathrm{mg} / \mathrm{dL}(<1.29 \mathrm{mmol} / \mathrm{L})$ for female. Hypertension (HTN) was defined when the systolic blood pressure was $\geq 130 \mathrm{~mm} \mathrm{Hg}$ and/or diastolic blood pressure was $\geq 85 \mathrm{~mm} \mathrm{Hg}$ in addition to receiving any medication for hypertension. Abnormal glucose metabolism was considered when HbA1c ( $\geq 5.7$ ) or when patients were known to have type 2 diabetes (T2DM). A combination of two or more of these risk factors was used to assess cut off values for BMI. Body mass index (BMI) values classified into groups as obese Grade I (BMI=30-34.9kg/m²), obese Grade II $\left(B M I=35.0-39.9 \mathrm{~kg} / \mathrm{m}^{2}\right)$ and morbidly obese (obese Grade III) $\left(\mathrm{BMI} \geq 40 \mathrm{~kg} / \mathrm{m}^{2}\right)$. The total number of cohort were separated on basis of age values into 6 groups: $<30$ years, 30-39 years, $40-49$ years, $50-59$ years, 60-69 years and $\geq 70$ years.
\end{abstract}

Main results: Of the 1526 participants analyzed, 476 (30.6\%) were male and 1059 (69.4\%) were female. Age was $51.2 \pm 12.8$ (minimum 18 years and maximum 105 years). MetS was present in 1060 cases (69.5\%) where 328 (30.9\%) were male and 732 (69.1\%) were female with female to male ratio 2.2:1, $\mathrm{P}=0.7$. Males were significantly older than females in MetS patients $(55.0 \pm 12.4$ vs. $53.0 \pm 12.3$ respectively, $\mathrm{p}=0.01)$. BMI was significantly higher in females than males with MetS patients ( $36.5 \pm 6.0$ vs. $34.3 \pm 3.7$ respectively, $p<0.0001)$. Female patients with MetS were significantly higher HDL and HbA1c $>5.6$ or T2DM. Patients with HTN were 18 -fold to possess MetS (OR=18.5; 95\% confidence interval [CI] $13.0,26.5$, or had been diagnosed with T2DM or having HbA1c $>5.6$ (OR=15.3; 95\% CI=11.6, 20.1), ( $<<0.0001)$, have elevated plasma TG levels (OR=13.8; 95\% CI=9.2, 20.7) and were also more likely to have low levels of HDL (OR=9.3; 95\% CI=7.1, 12.1). HbA1c $>5.6$ or T2DM has the highest frequency among the MetS phenotypes $89.2 \%$, $\mathrm{p}<0.0001$. MetS prevalence is consistently statistically significant with increasing age until the sixth decade then starts to decline $(\mathrm{p}<0.0001)$. Moreover, higher prevalence is among age group 50-59 years of age in females. MetS prevalence was higher among BMI=30-34 group in all patients and both genders. Thus, the mean of BMI among MetS is statistically significant decreased with advanced age in total population and both gender. The mean of BMI among MetS is statistically significant negatively correlated with increasing with advanced age $(\mathrm{r}=-0.1, \mathrm{p}<0.0001)$.

Conclusion: The prevalence of metabolic syndrome among obese Saudis is relatively high. Old age and obesity can be regarded as related factors.

Keywords: Metabolic syndrome; Obeisty

\section{Introduction}

Metabolic syndrome (MetS) is a cluster of metabolic factors. MetS was initially observed in 1923 by Kyln, who described the clustering of hypertension, hyperglycaemia and gout as the syndrome. [1] Subsequently, several other metabolic abnormalities have been associated with this syndrome, including obesity, microalbuminuria, and abnormalities in fibrinolysis and coagulation. In 1988, Gerald [2] reintroduced the concept of Syndrome $\mathrm{X}$ for the clustering of cardiovascular risk factors like hypertension (HTN), glucose intolerance, high triglycerides (TG) and low highdensity lipoprotein (HDL) concentration. [3] The first official definition of MetS put forward by a working group of the
World Health Organization (WHO) in 1999, a number of different definitions have been proposed. There have been several definitions of MS, but the most commonly used criteria for definition at present are from the National Cholesterol Education Program (NCEP) Adult Treatment Panel III (ATP III), the International Diabetes Federation (IDF), and the World Health Organization (WHO) [4-9].

Risk factor clustering in the MetS cannot be explained by chance alone [10]. Therefore, the syndrome is widely accepted as an important risk factor for cardiovascular disease (CVD) morbidity and mortality and type 2 diabetes mellitus (T2DM) 
[4,11-14]. MetS increases the risk of developing T2DM by three to five-fold and CVD by two-fold, and it has become a major public health challenge around the world $[7,15,16]$. As the various abnormalities of MetS may be documented up to 10 years before the detection of T2DM or CVD, there is a potential to prevent both of them in persons identified with MetS [9]. The purpose of identifying people with the MetS is to reduce the long-term risk of developing T2DM, CVD, and other forms of atherosclerotic disease, chronic renal disease, obstructive sleep apnea, nonalcoholic fatty liver disease, and gout [17]. Of all the factors, obesity has been shown to be the most important index. An excess of adipose tissue can be a source of proinflammatory cytokines which may be linked to a greater risk for further insulin resistance as well as atherogenesis [18]. The prevalence of the metabolic syndrome and CVD is expected to rise dramatically in parallel to the global obesity epidemic. It is commonly observed that the probability of having metabolic abnormalities, including MetS, increases with the level of obesity. For example, by comparison with normal weight men, the odds of having MetS ranged from 5.2 to 25.2 to 67.7 times across overweight, moderately obese, and severely obese men in the National Health and Nutrition Examination Survey III (NHANES III) [19]. A strong association was established between high BMI and the development of metabolic disorders within the subsequent 10 years of follow-up [20]. Obesity is defined by the BMI, as weight in kilograms divided by the square of the height in meters $\left(\mathrm{kg} / \mathrm{m}^{2}\right)$. WHO classifies obesity as a BMI greater than or equal to 30 , and extreme obesity as a BMI greater than or equal to 40 . Studies by the NHANES Center have shown an upper trend in the prevalence of obesity in the adult populations, particularly in the past 20 years. It is estimated that $27 \%$ of adults in the United States (20 to 74 years) are obese $[21,22]$. The prevalence of obesity (BMI $\geq 30 \mathrm{~kg} / \mathrm{m}^{2}$ ) has been steadily increasing, particularly in the younger generation.

Frequently obesity-associated dyslipidemia is a factor seen in MetS. MetS affects $23 \%$ of the Western world. Eighty percent of patients with MetS have T2DM. These patients present with a particularly atherogenic type of hyperlipidemia, that is, elevated fasting TG levels and low levels of HDL. However, the estimated prevalence of MetS differs between various populations, because variations exist in the frequencies of metabolic risk components [18]. The MetS has gained a great interest worldwide because of its increasing prevalence [9]. MetS affects around 20\%-25\% of the world population and its prevalence has been globally increased, as a result of Westernization of lifestyle with less physical activity and increased obesity [16]. Al-Nozha and colleagues previously reported that MetS was almost $40 \%$ among adults in a kingdomwide sample population taken from 1995-2000 [23]. Since then, other epidemiologic studies conducted within the Arab Peninsula confirmed the same high prevalence [24-26]. Despite the prevalence of MetS is well known in various populations, there is no in-depth information available about the prevalence of MetS and the individual components within particular combined subgroups of sex, BMI and age. However, recent studies on the clustering of the metabolic risk factors in the form of MetS in Saudi population are limited. There is little information on the prevalence of MS and obesity among Saudis across obese categories. Therefore, the aim of this study was to determine the prevalence of MetS in obese Saudi population.

\section{Methods}

We analyzed 1526 obese participants who are equal to or older than 18 years old. All cases were from the population of the primary health at King Fahad Armed Forces Hospital. All data were collected by personal interview and on the basis of a review of electronic medical records. Physician and nurse interviewers measured and recorded weight $(\mathrm{kg})$ and height $(\mathrm{cm})$. Metabolic risk factors were defined using the 2006 IDF criteria that define elevated triglyceride as $\geq 150 \mathrm{mg} / \mathrm{dL}(\geq 1.7 \mathrm{mmol} / \mathrm{L})$ and reduced $\mathrm{HDL}$ as $<40 \mathrm{mg} / \mathrm{dL}$ $(<1.03 \mathrm{mmol} / \mathrm{L})$ for male and as $<50 \mathrm{mg} / \mathrm{dL}(<1.29 \mathrm{mmol} / \mathrm{L})$ for female [27]. HTN was defined when the systolic blood pressure was $\geq 130 \mathrm{~mm} \mathrm{Hg}$ and/or diastolic blood pressure was $\geq 85 \mathrm{~mm} \mathrm{Hg}$ in addition to receiving any medication for hypertension. Abnormal glucose metabolism was considered when HbA1c ( $\geq 5.7)$ or when patients were known to have type 2 diabetes. A combination of two or more of these risk factors was used to assess cut off values for BMI. Body mass index (BMI) values classified into groups as obese Grade I (BMI $\left.=30-34.9 \mathrm{~kg} / \mathrm{m}^{2}\right)$, obese Grade II $(\mathrm{BMI}=35.0-39.9 \mathrm{~kg} /$ $\mathrm{m}^{2}$ ) and morbidly obese (obese Grade III) (BMI $\geq 40 \mathrm{~kg} / \mathrm{m}^{2}$ ) [28]. The total number of cohort were separated on basis of age values into six groups: $<30$ years, 30-39 years, $40-49$ years, 50-59 years, $60-69$ years and $\geq 70$ years.

\section{Statistical Analysis}

Unpaired t-test analysis and Chi square $\left(\mathrm{X}^{2}\right)$ test (categorical data comparison) were used between variables to estimate the significance of different between groups for demographic and clinical laboratory. The independent relationship between the stratified BMI and the odds ratio of having MetS were analyzed using Chi square $\left(\mathrm{X}^{2}\right)$. All statistical analyses were performed using SPSS Version 22.0. The difference between groups was considered significant when $\mathrm{P}<0.05$.

\section{Results}

Table 1: Basic characteristics of the population under study (means \pm SD or number (\%)).

\begin{tabular}{|c|c|c|}
\hline \multicolumn{2}{|l|}{ Parameters } & Total \\
\hline \multicolumn{2}{|l|}{$\mathrm{n}(\%)$} & 1526 \\
\hline \multicolumn{2}{|l|}{ Age (years) } & $51.2 \pm 12.8$ \\
\hline \multirow{2}{*}{ Gender } & Male & $467(30.6)$ \\
\hline & Female & $1059(69.4)$ \\
\hline \multirow{3}{*}{ Body mass index groups $\left(\mathrm{kg} / \mathrm{m}^{2}\right)$} & $35.0-34.9$ & $877(57.5)$ \\
\hline & $35.0-39.9$ & $456(29.9)$ \\
\hline & $\geq 40.0$ & 193(12.6) \\
\hline \multicolumn{2}{|l|}{ Body mass index $\left(\mathrm{kg} / \mathrm{m}^{2}\right)$} & $35.7 \pm 5.5$ \\
\hline \multicolumn{2}{|c|}{ HbA1c $>5.6$ or Type 2 diabetes mellitus } & $1110(72.7)$ \\
\hline \multicolumn{2}{|l|}{ Hypertension } & $689(45.2)$ \\
\hline \multicolumn{2}{|l|}{ Triglyceride $(\geq 1.7 \mathrm{mmol} / \mathrm{l})$} & $513(33.6)$ \\
\hline \multicolumn{2}{|c|}{ High density lipoprotein $(<1.29 \mathrm{mmol} / \mathrm{l})$} & $837(54.8)$ \\
\hline
\end{tabular}


Of the 1526 participants analyzed, 476 (30.6\%) were male and 1059 (69.4\%) were female. Age was 51.2 \pm 12.8 (minimum 18 years and maximum 105 years), Table 1. MetS was present in 1060 cases (69.5\%) where 328 (30.9\%) were male and 732 (69.1\%) were female with female to male ratio 2.2:1, $\mathrm{P}=0.7$, Table 2 . Males were significantly older than females in MetS patients $(55.0 \pm 12.4$

Table 2: Characteristics of the population with metabolic syndrome under study stratified by gender (means \pm SD or number $(\%))$. in females than males with MetS patients $(36.5 \pm 6.0$ vs. $34.3 \pm 3.7$ respectively, $\mathrm{p}<0.0001)$. Female patients with metabolic syndrome were significantly higher HDL and HbA1c $>5.6$ or Type 2 diabetes mellitus. vs. $53.0 \pm 12.3$ respectively, $\mathrm{p}=0.01$ ). BMI was significantly higher

\begin{tabular}{|c|c|c|c|c|}
\hline \multirow{2}{*}{ Parameters } & \multirow{2}{*}{ Total } & \multicolumn{2}{|c|}{ Gender } & \multirow{2}{*}{$P$ value } \\
\hline & & Male & Female & \\
\hline n (\%) & $1060(69.5)$ & $328(30.9)$ & $732(69.1)$ & 0.7 \\
\hline Age (years) & $53.6 \pm 12.3$ & $55.0 \pm 12.4$ & $53.0 \pm 12.3$ & 0.01 \\
\hline Body mass index $\left(\mathrm{kg} / \mathrm{m}^{2}\right)$ & $35.8 \pm 5.5$ & $34.3 \pm 3.7$ & $36.5 \pm 6.0$ & $<0.0001$ \\
\hline HbA1c $>5.6$ or Type 2 diabetes mellitus & $946(89.2)$ & $281(85.7)$ & $665(90.8)$ & 0.01 \\
\hline Hypertension & $652(61.5)$ & $204(62.2)$ & $448(61.2)$ & 0.8 \\
\hline Triglyceride $(\geq 1.7 \mathrm{mmol} / \mathrm{l})$ & $486(45.8)$ & 183(55.8) & $303(41.4)$ & $<0.0001$ \\
\hline High density lipoprotein $(<1.29 \mathrm{mmol} / \mathrm{l})$ & $743(70.1)$ & $216(65.9)$ & $527(72.0)$ & 0.04 \\
\hline
\end{tabular}

Table 3: The risk of metabolic syndrome phenotype among metabolic syndrome population

\begin{tabular}{|c|c|c|}
\hline Parameters & Odd Ratio & P value \\
\hline $\begin{array}{c}\text { HbA1c }>5.6 \text { or Type 2 diabetes } \\
\text { mellitus }\end{array}$ & $15.3(11.6-20.1)$ & $<0.0001$ \\
\hline Hypertension & $18.5(13.0-26.5)$ & $<0.0001$ \\
\hline Triglyceride ( $\geq 1.7 \mathrm{mmol} / \mathrm{l})$ & $13.8(9.2-20.7)$ & $<0.0001$ \\
\hline $\begin{array}{c}\text { High density lipoprotein } \\
(<1.29 \mathrm{mmol} / \mathrm{l})\end{array}$ & $9.3(7.1-12.1)$ & $<0.0001$ \\
\hline
\end{tabular}

Table 3 shows patients HTN with were 18-fold to possess MetS $(\mathrm{OR}=18.5 ; 95 \%$ confidence interval $[\mathrm{CI}]=13.0,26.5$, or had been diagnosed with T2DM or having HbA1c $>5.6$ (OR=15.3; 95\% CI=11.6, 20.1), $(\mathrm{p}<0.0001)$, have elevated plasma TG levels (OR=13.8; $95 \%$ $\mathrm{CI}=9.2,20.7)$ and were also more likely to have low levels of HDL $(\mathrm{OR}=9.3 ; 95 \% \mathrm{CI}=7.1,12.1)$. Table 4 shows the numbers (\%) of metabolic syndrome according to metabolic phenotypes across different age groups. HbA1c $>5.6$ or T2DM has the highest frequency among the MetS phenotypes $89.2 \%, \mathrm{p}<0.0001$.
Table 4: Numbers (\%) of metabolic syndrome according to HbA1c>5.6 or Type 2 diabetes mellitus, hypertension (HTN), Triglyceride (TG) $(\geq 1.7 \mathrm{mmol} / \mathrm{l})$ and High-density lipoprotein (HDL) $(<1.29 \mathrm{mmol} / 1)$ across different age groups.

\begin{tabular}{|c|c|c|c|c|}
\hline Age (Years) & $\begin{array}{c}\text { Hba1c }>5.6 \\
\text { or Type 2 } \\
\text { Diabetes } \\
\text { Mellitus }\end{array}$ & HTN & TG & HDL \\
\hline$<30$ & $21(75.0)$ & $8(28.6)$ & $12(42.9)$ & $26(92.9)$ \\
\hline $30-39$ & $77(75.5)$ & $29(28.4)$ & $61(59.8)$ & $86(84.3)$ \\
\hline $40-49$ & $212(86.2)$ & $101(41.1)$ & $117(47.6)$ & $190(77.2)$ \\
\hline $50-59$ & $325(91.3)$ & $253(71.1)$ & $153(43.0)$ & $235(66.0)$ \\
\hline $60-69$ & $214(93.4)$ & $177(77.3)$ & $102(44.5)$ & $145(63.3)$ \\
\hline$\geq 70$ & $97(98.0)$ & $84(84.4)$ & $41(41.4)$ & $61(61.6)$ \\
\hline Total & $946(89.2)$ & $652(61.5)$ & $486(45.8)$ & $743(70.1)$ \\
\hline P value & $<0.0001$ & $<0.0001$ & 0.05 & $<0.0001$ \\
\hline
\end{tabular}

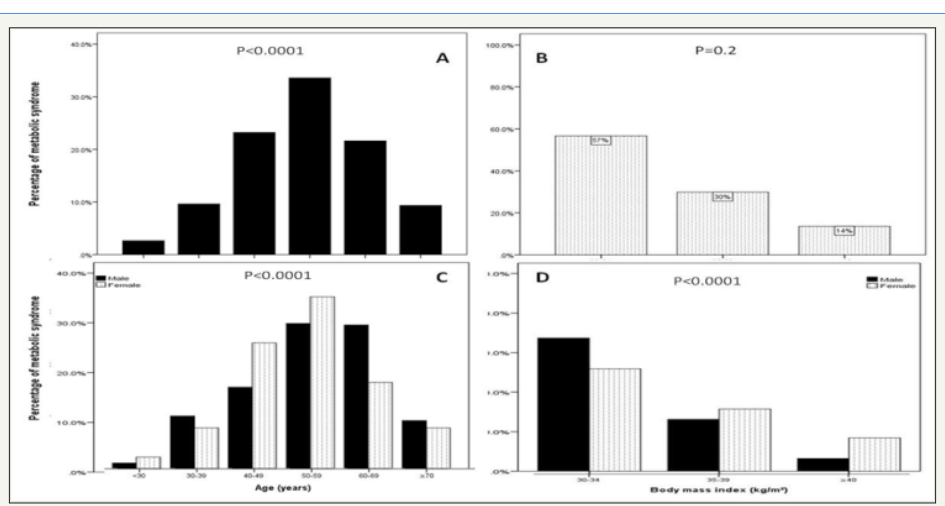

Figures 1: Percentages of women with metabolic syndrome $\geq$ across different age groups $(\mathrm{A})$ and in relation to gende (C) and body mass index ranges (B) and in relation to gender (D). 
MetS prevalence is consistently statistically significant with increasing age until the sixth decade then starts to decline $(\mathrm{p}<0.0001)$, Figure 1 A. Moreover, higher prevalence is among age group 50-59 years of age in females, Figure $1 \mathrm{C}$. MetS prevalence was higher among BMI=30-34 group in all patients and both genders,
Figure $1 \mathrm{~B}$ and D. Thus, the mean of BMI among MetS is statistically significant decreased with advanced age in total population and both gender, Figure 2. The mean of BMI among MetS is statistically significant negatively correlated with increasing with advanced age $(r=-0.1, p<0.0001)$.

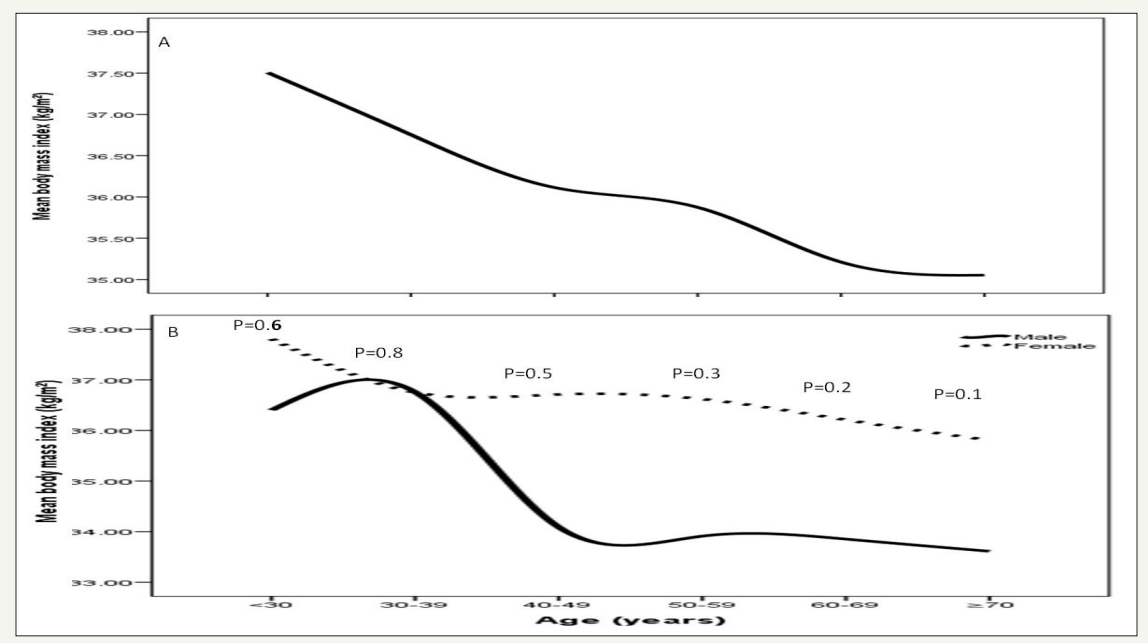

Figures 2: Mean body mass index $\mathrm{kg} / \mathrm{m}^{2}$ in patients with metabolic syndrome across different age groups (A) stratified to gender and in relation to gender (B).

\section{Discussion}

Proper definition of the causes and risk factors of MetS is mandatory for prevention and/or treatment of MetS. In addition to the well-defined risk factors for MetS, there are diseases and conditions that lead to MetS secondarily. Knowing these conditions and defining them as risk factors is of importance in the approach toward patients with MetS. In the present study, in which we aimed to determine the factors that would lead to secondary MetS among obese patients, the characteristics of 1526 obese patients with MetS were evaluated. Considering the IDF criteria for MetS diagnosis, we showed that around $69.5 \%$ of the cohort analyzed presented the syndrome, which was nonsignificantly more prevalent in females individuals $(69.4 \%, \mathrm{p}=0.7)$. Noticeably higher than the estimated global prevalence and finding is higher than other national and regional studies [6,29-36]. In discordance with other, the current study showed that the prevalence of MetS was noted to decrease from obesity class I to II, although the prevalence in obesity class III was slightly lower [37]. Marchesini et al. [38] showed that the prevalence of MetS in their obese subjects increased with a rising obesity class and MetS was significantly associated with BMI.

In the last two decades, health professionals have noticed that obesity is closely related to the development of MetS; at the same time, they have also noticed that many Asian races are more susceptible in developing abdominal obesity even with normal BMI. Genetic predispositions as well as adopting western lifestyles have been considered to contribute to such phenomenon [39].

Obesity is an alarming public health challenge of the $21^{\text {st }}$ century and an important factor in developing MetS and many chronic diseases, such as CVD, T2DM and HTN [40]. Previous studies have documented an increased risk of mortality due to excess body weight as well as MetS $[41,42]$. In the present sample, it is also noteworthy that $30.5 \%$ of obese patients did not have MetS. Thus, although there is a robust relationship between level of obesity and the presence of multiple risk factors, there is considerable variability in the presence of MetS within BMI categories. The idea that some obese individuals appear healthy and display none of the traditional risk factors for chronic disease, including dyslipidemia and insulin resistance, has been reported previously [43]. Since class III obesity (morbid or extreme obesity) is associated with the most severe health complications, the incidence of HTN, stroke, heart disease, T2DM, and peripheral vascular disease will increase substantially in the future. The prevalence of severe obesity $\left(\mathrm{BMI} \geq 30 \mathrm{~kg} / \mathrm{m}^{2}\right.$ ) has been steadily increasing, particularly in the younger generation. This may be explained by the fact that fast food restaurants have been quickly gaining popularity in Saudi Arabia, selling unhealthy foods. In addition, market dissemination of the automobile greatly increased during the same period. Several previous studies investigated the metabolic abnormalities associated with obesity, but few data are available in super-obese patients. Some of these studies reported that certain parameters of metabolic status worsen as the severity of SO increases, whereas others found that the metabolic situation remains the same or even improves with more severe stages of obesity [44-46]. The reasons for the conflicting results in the various studies are unknown but may occur secondarily to the limited numbers of study subjects in some of these reports.

In Saudi Arabia the prevalence of MetS was found to be $39.8 \%$ (34.4\% in men and 29.2\% in women) and 31.6\% (45.0\% in men and $35.4 \%$ in women), according to the NCEP ATP III and IDF criteria, respectively [36]. Another national study found the prevalence to be $39.3 \%$ in 2005 , using the 2001 ATP III criteria [23]. This indicates 
that there might be some changes in the risk factors especially among females that can be explained by the fact that females, most of whom are housewives in our society, are more prone to obesity after child birth, besides, women transition from the premenopausal to the postmenopausal stage with substantial metabolic changes and estrogen deficiency might lead to an increased predisposition to metabolic syndrome. The difference in prevalence of MetS between men and women may be related to differences in body fat distribution: men have more visceral and hepatic fat, whereas women have more total body fat [47]. Differences in distribution of fat with age and the cardiometabolic effects of menopause may explain the diminished sex difference in MetS prevalence seen with older age $[47,48]$. In females, menopause and estrogen deficiency appears to be independent predisposing factor for the development of most of the components of the MetS [49,50].

In this study, the old age group (50-59 years) was the most affected, whereas it is the elderly who are usually expected to have a higher prevalence of HTN, abnormal cholesterol, or being overweight, because age is a non-modifiable risk factor for these conditions. It can be explained by the aging process. This is also supported by a study in United Arab Emiates that showed a positive association between the prevalence of metabolic syndrome and age [51]. In some studies, prevalence estimates for MetS are found to plateau or drop off after the sixth or seventh age decade in both sexes or only in men [52-55]. This observation might be due to a survival effect or participation bias, as individuals prone to obesity-related morbidity and mortality have already died or decline to participate in a study [56]. The observed trend of increasing MetS prevalence with age can be explained by the large number of people developing metabolic complications by the time they are aged $\geq 50$ years (i.e. more than $85 \%$ of the individuals have at least one metabolic risk factor). Due to the age-related rises of HTN, obesity and glucose a more similar make-up of MetS was seen in the elderly, whereas in younger people, the MetS profile was more heterogeneous and differed more by sex. While it may also depend on the definition used for MetS even if the same definition was used, different trends were observed between countries [52,57]. This underpins the importance of estimating the country-specific prevalence of MetS. One reason for this finding is that the population of Saudi Arabia is changing from its traditional lifestyle to westernised ways and so becoming more subject to similar diseases, the young being more prone in this regard. In contrast, older people, who are less inclined to change their habits, reflected healthier findings. It would be beneficial to identify lifestyle changes among the elderly that could determine the increased tendency to develop risk factors for the diseases of developed countries. It would also be interesting to determine to what extent these risk factors are associated with CVD, stroke and/or T2DM among Saudi population, since most studies have been conducted in Caucasian populations.

The prevalence of individual metabolic comorbidities of the metabolic syndrome in the current study, according to the IDF definition, was, raised fasting blood sugar, reduced HDL, raised blood pressure and high TG was 72.7, 54.8, 45.2, and 33.6\%, respectively. In discordance to findings were observed in US
NHANES III 2003-2006 survey indicating a high prevalence of components of MetS, as defined by ATP III. Among the 3423 adults, abdominal obesity was present in 53\%, elevated blood pressure in $40 \%$, and hyperglycemia in 39\%. These were the most frequently occurring risk factors for MetS, regardless of whether one examined the crude or age-adjusted estimates [58].

MetS is an asymptomatic, pathophysiological state characterised by obesity, insulin resistance, hypertension, dysglycaemia, and dyslipidaemia. The clinical utility of MetS has been criticized for quit some years. Criticism is related to the predictive value of MetS for CVD. MetS is found to have no greater predictive value for CVD compared to the individual components. Furthermore, all MetS components are weighted equally while it is clear that some risk factors are more important for risk prediction. Also, continuous variables are dichotomized and MetS is operationalized as a combination of three or more of the five components, which results in a loss of predictive power $[59,60]$. In the current ATPIII definition, only blood pressure and fasting glucose are used for targeted risk factor interventions in clinical practice. Though, interventions are seldom started at the levels proposed by the ATPIII.

\section{Strengths and limitations}

One of the strength of our study, the large number of participants allowed us to explore trends within detailed clusters of sex, BMI and age, which has not been done before. Our results should be interpreted in light of the study's limitations. First, most of the patients enrolled were already on treatment for hypertension, diabetes and hypertriglyceridemia, which imposed some limitations on the study. We tried to overcome these by obtaining the necessary sample size and by using data documented before treatment. Finally, as this was a hospital-based, retrospective study, the findings do not represent the whole Saudi population or the local community. Further larger population-based studies are necessary to support our findings. Another limitation of the present study was having considered only overall obesity (assessed by BMI) and not abdominal obesity (measured by waist circumference), which is known to bear a close relationship with the target diseases.

\section{Conclusion}

It can be concluded from this study that the prevalence of metabolic syndrome among obese Saudis is relatively high. Old age and obesity can be regarded as related factors.

\section{Acknowledgment}

We are grateful to the staffs from the Primary care department at King Fahad Armed Forces Hospital for their valuable contributions in data collection. The authors have no conflict of interest to disclose.

\section{References}

1. Kylin E (1923) Studien ueber das hypertonie-hyperglykamie -hyperurikamiesyndrom. Zentrallblatt fuer Innere Medizin 44: 105-127.

2. Isomaa B, Almgren P, Tuomi T, Forsen B, Lahti K, et al. (2001) Cardiovascular morbidity and mortality associated with the metabolic syndrome. Diabetes Care 24(4): 683-689. 
3. Reaven GM (1988) Banting lecture 1988. Role of insulin resistance in human disease. Diabetes 37(12): 1595-1607.

4. National Cholesterol Education Program (NCEP) expert panel on detection, evaluation, and treatment of high blood cholesterol in adults (Adult treatment panel III) (2002) Third report of the National Cholesterol Education Program (NCEP) expert panel on detection, evaluation, and treatment of high blood cholesterol in adults (Adult treatment panel III) final report. Circulation 106(25): 3143-3421.

5. Tan BT, Kantilal HK, Singh R (2008) Prevalence of metabolic syndrome among malaysians using the international diabetes federation, national cholesterol education program and modified world health organisation definitions. Mal J Nutr 14(1): 65-77.

6. (2006) International Diabetes Federation: The IDF Consensus Worldwide Definition of the MS.

7. Zimmet P, Maglian D, Matsuzawa Y, Alberti G, Shaw J (2005) The metabolic syndrome: a global public health problem and a new definition. J Atherosclera Thromb 12(6): 259-300.

8. Alberti KG, Zimmet PZ (1998) Definition, diagnosis and classification of diabetes mellitus and its complications. Part 1: diagnosis and classification of diabetes mellitus provisional report of a WHO consultation. Diabet Med 15(7): 539-553.

9. (1999) WHO (World Health Organization). definition, diagnosis and classification of diabetes mellitus and its complications. report of a who consultation. Part 1: diagnosis and classification of diabetes mellitus. Department of Non-communicable Disease Surveillance. Geneva, Switzerland.

10. Grundy S (2006) Does a diagnosis of metabolic syndrome have value in clinical practice? Am J Clin Nutr 83(6): 1248-1251.

11. Liberopoulos EN, Mikhalidis DP, Elisaf MS (2005) Diagnosis and management of the metabolic syndrome in obesity. Obes Rev 6(4): 283296.

12. Bener, Mohammad AG, Ismail AN, Zirie M, Abdullatef WK, et al. (2010) Gender and age-related differences in patients with the metabolic syndrome in a highly endogamous population. Bosnian Journal of Basic Medical Sciences 10(3): 210-217.

13. Moller DE, Kaufman KD (2005) Metabolic syndrome: a clinical and molecular perspective. Annual Review of Medicine 56: 45-62.

14. CL Scott (2003) Diagnosis, prevention and intervention for the metabolic syndrome. American Journal of Cardiology 92(1A): 35i-42i.

15. Alberti KG, Eckel RH, Grundy SM, Zimmet PZ, Cleeman JI, et al. (2009) Harmonizing the metabolic syndrome: A joint interim statement of the international diabetes federation task force on epidemiology and prevention; national heart, lung, and blood institute; american heart association; world heart federation; international atherosclerosis society; and international association for the study of obesity. Circulation 120(16): 1640-1645.

16. Kaur J (2014) A comprehensive review on metabolic syndrome. Cardiol Res Pract 2014: 943162

17. Petrucelli O (2008) The Metabolic syndrome. Northeast Florida Medicine 59: 18-21.

18. Shoelson SE, Lee J, Goldfine AB (2006) Inflammation and insulin resistance. J Clin Invest 116(7): 1793-1801.

19. Park YW, Zhu S, Palaniappan L, Heshka S, Carnethon MR, et al. (2003) The metabolic syndrome: prevalence and associated risk factor findings in the US population from the Third National Health and Nutrition Examination Survey, 1988-1994. Arch Intern Med 163(4): 427-436.

20. Hwang LC, Tsai CH, Chen TH (2006) Overweight and obesity-related metabolic disorders in hospital employees. J Formos Med Assoc 105(1): 56-63.
21. Flegal KM, Carroll MD, Ogden CL, Johnson CL (2002) Prevalence and trends in obesity among US adults, 1999-2000. JAMA 288(14): 17231927.

22. Massie BM (2002) Obesity and heart failure: risk factor or mechanism? (editorial). N Engl J Med 347(5): 358-359.

23. Al Nozha M, Al Khadra A, Arafah MR, Al Maatouq MA, Khalil MZ, et al. (2005) Metabolic syndrome in Saudi Arabia. Saudi Med J 26(12): 19181925.

24. Saadi H, Nagelkerke N, Carruthers SG, Benedict S, Abdulkhalek S, et al. (2008) Association of TCF7L2 polymorphism with diabetes mellitus, metabolic syndrome, and markers of beta cell function and insulin resistance in a population-based sample of Emirati subjects. Diabetes Res Clin Pract 80(3): 392-398.

25. Khader Y, Bateiha A, El Khateeb M, Al Shaikh A, Ajlouni K (2007) High prevalence of the metabolic syndrome among Northern Jordanians. J Diabetes Complications 21(4): 214-219.

26. Harzallah F, Alberti H, Ben Khalifa F (2006) The metabolic syndrome in an Arab population: a first look at the new International Diabetes Federation criteria. Diabet Med 23(4): 441-444.

27. Alberti KGMM, Zimmet P (2006) Metabolic syndrome- a new worldwide definition. A consensus statement from the International Diabetes Federation. Diabetic Medicine 23(5): 469-480.

28. Chen YM, Ho SC, Lam SS, Chan SS (2006) Validity of body mass index and waist circumference in the classification of obesity as compared to percent body fat in chinese middle-aged women. Int J Obes (Lond) 30(6): 918-925

29. Al Lawati J, Mohammed A, Al Hinai H, Jousilahti P (2003) Prevalence of the Metabolic Syndrome Among omani adults. Diabetes Care 26(6): 1781-1785.

30. Alzahrani A, Karawagh A, Alshahrani F, Naser T, Ahmed A, et al. (2012) Prevalence and predictors of metabolic syndrome among healthy saudi adults. Br J Diabet Vasc Dis 12(2):78.

31. Al Daghri NM (2010) Extremely high prevalence of metabolic syndrome manifestations among Arab youth: A call for early intervention. Eur J Clin Invest 40(12): 1063-1066.

32. Al Shaibani H, El Batish M, Sorkhou I, Al Shamali N, Al Namash H, et al. (2004) Prevalence of insulin resistance syndrome in a primary health care center in Kuwait. Fam Med 36(8): 540.

33. Kozan O, Oguz A, Abaci A, Erol C, Ongen Z, et al. (2007) Prevalence of the metabolic syndrome among Turkish adults. Eur J Clin Nutr 61(4): 548-553.

34. Malik M, Razig SA (2008) The prevalence of the metabolic syndrome among the multiethnic population of the United Arab Emirates: A report of a national survey. Metab Syndr Relat Disord 6(3): 177-186.

35. Zabetian A, Hadaegh F, Azizi F (2007) Prevalence of metabolic syndrome in Iranian adult population, concordance between the IDF with the ATPIII and the WHO definitions. Diabetes Res Clin Pract 77(2): 251-257.

36. Khalid Al Rubeaan, Bawazeer N, Yousuf Al F, Amira YF, Abdulrahman A, et al. (2018) Prevalence of metabolic syndrome in Saudi Arabia-a cross sectional study BMC Endocrine Disorders 18: 16.

37. Ismail MF (2012) Metabolic syndrome among obese Qataris attending primary health care centers in Doha, 2010. J Fam Community Med 19(1): 7-11.

38. Marchesini G, Melchionda N, Apolone G, Cuzzolaro M, Mannucci E, et al (2004) The metabolic syndrome in treatment-seeking obese persons. Metabolism 53(4): 435-440.

39. Palaniappan LP, Wong EC, Shin JJ, Fortmann SP, Lauderdale DS (2011) Asian Americans have greater prevalence of metabolic syndrome despite lower body mass index. Int J Obes (Lond) 35(3): 393-400. 
40. Yeh WT, Chang HY, Yeh CJ, Tsai KS, Chen HJ, et al. (2005) Do centrally obese Chinese with normal BMI have increased risk of metabolic disorders? Int J Obes (Lond) 29(7): 818-825.

41. Baik I, Ascherio A, Rimm EB, Giovannucci E, Spiegelman D, et al. (2000) Adiposity and mortality in men. Am J Epidemiol. 152(3): 264-271.

42. Lakka HM, Laaksonen DE, Lakka TA, Niskanen LK, Kumpusalo E, et al. (2002) The metabolic syndrome and total and cardiovascular disease mortality in middle-aged men. JAMA 288(21): 2709-2716.

43. Karelis AD, St Pierre DH, Conus F, Rabasa Lhoret R, Poehlman ET (2004) Metabolic and body composition factors in subgroups of obesity: what do we know? J Clin Endocrinol Metab 89(6): 2569-2575.

44. Dixon JB, O Brien P (2001) Adisparity between conventional lipid and insulin resistance markers at body mass index levels greater than $34 \mathrm{~kg}$ $\mathrm{m}^{2}$. Int J Obes Relat Metab Disord 25: 793-797.

45. Wolf AM, Buffington C, Beisiegel U (2006) Comparison of metabolic risk factors between severely and very severely obese patients. Obesity (Silver Spring) 14(12): 2177-2183.

46. Nguyen NT, Magno CP, Lane KT, Hinojosa MW, Lane JS (2008) Association of hypertension, diabetes, dyslipidemia, and metabolic syndrome with obesity: findings from the national health and nutrition examination survey, 1999 to 2004. J Am Coll Surg 207(6): 928-934.

47. Pradhan AD (2014) Sex differences in the metabolic syndrome: implications for cardiovascular health in women. Clinical Chemistry $60(1): 44-52$

48. Rosano GM, Vitale C, Marazzi G, Volterrani M (2007) Menopause and cardiovascular disease: the evidence. Climacteric 10 (Suppl 1): 19-24.

49. Carr MC (2003) The emergence of the metabolic syndrome with menopause. J Clin Endocrinol Metab 88(6): 2404-2411.

50. Ben Ali S, Belfki Benali H, Aounallah Skhiri H, Traissac P, Maire B, et al. (2014) Menopause and metabolic syndrome in Tunisian women. Biomed Res Int
51. Aguilar M, Bhuket T, Torres S, Liu B, Wong RJ (2015) Prevalence of the metabolic syndrome in the United States, 2003-2012. JAMA 313(19): 1973-1974.

52. Cameron AJ, Magliano DJ, Zimmet PZ, Welborn T, Shaw JE (2007) The metabolic syndrome in Australia: prevalence using four definitions. Diabetes Research and Clinical Practice77(3): 471-478.

53. Deepa M, Farooq S, Datta M, Deepa R, Mohan V (2007) Prevalence of metabolic syndrome using WHO, ATPIII and IDF definitions in Asian Indians: the Chennai Urban Rural Epidemiology Study (CURES- 34). Diabetes/Metabolism Research and Reviews. 23(2): 127-134.

54. Adams RJ, Appleton S, Wilson DH, Taylor AW, Dal Grande E, et al. (2005) Population comparison of two clinical approaches to the metabolic syndrome: implications of the new International diabetes federation consensus definition. Diabetes Care 28(11): 2777-2779.

55. Ford ES, Li C, Zhao G (2010) Prevalence and correlates of metabolic syndrome based on a harmonious definition among adults in the US. Journal of Diabetes 2(3): 180-193.

56. Zamboni M, Mazzali G, Zoico E, Harris TB, Meigs JB, et al. (2005) Health consequences of obesity in the elderly: a review of four unresolved questions. International Journal of Obesity 29(9): 1011-1029.

57. Gavrila D, Salmeron D, Egea Caparros JM, Huerta JM, Perez Martinez A, et al. (2011) Prevalence of metabolic syndrome in Murcia Region, a southern European Mediterranean area with low cardiovascular risk and high obesity. BMC Public Health 11: 562.

58. Ervin RB (2009) Prevalence of metabolic syndrome among adults 20 years of age and over, by sex, age, race and ethnicity, and body mass index: United States. National Health Statistics 5(13): 1-7.

59. Royston P, Altman DG, Sauerbrei W (2006) Dichotomizing continuous predictors in multiple regression: A bad idea. Statistics in Medicine 25(1): 127-141.

60. Sliem HA, Ahmed S, Nemr N, El Sherif I (2012) Metabolic syndrome in the middle east. Indian J Endocrinol Metab 16(1): 67-71.
Creative Commons Attribution 4.0 International License

For possible submissions Click Here

\section{Submit Article}

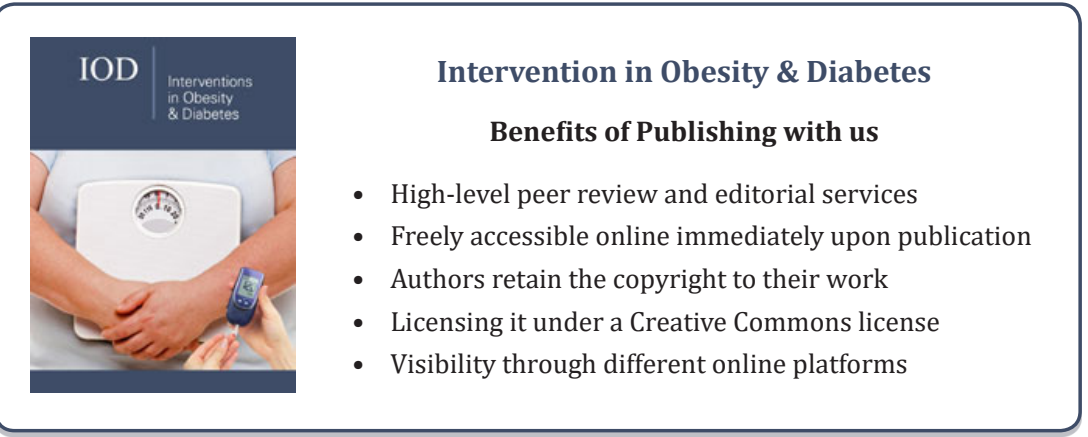

